SOI: $1.1 /$ TAS $\quad$ DOI: $10.15863 /$ TAS

International Scientific Journal Theoretical \& Applied Science

p-ISSN: 2308-4944 (print) e-ISSN: 2409-0085 (online)

Year: $2015 \quad$ Issue: $07 \quad$ Volume: 27

Published: $30.07 .2015 \quad \underline{\text { http://T-Science.org }}$

SECTION 9. Chemistry and chemical technology.
Oleg Ivanovich Yurchenko

Doctor of chemical sciences, Professor, Department of Chemistry,

V. N. Karazin Kharkiv National University, Ukraine yurchenko@karazin.ua

Aleksandr Nikolaevich Baklanov

Doctor of chemical sciences, Professor, Department of Chemistry,

V. N. Karazin Kharkiv National University, Ukraine baklanov227@mail.ru

Elena Aleksandrovna Belova

Candidate of chemical sciences, Docent, Department of Chemical and Food Technology, Ukrainian Engineering and Pedagogical Academy, Ukraine

Olga Sergeevna Kalinenko graduate student, Department of Chemistry, V. N. Karazin Kharkiv National University, Ukraine ok150388@mail.ru

Larisa Vladimirovna Baklanova Candidate of chemical sciences, Docent, Department of Occupational Health and Environmental Safety, Ukrainian Engineering and Pedagogical Academy, Ukraine baklanovalarisa@ya.ru

\title{
ULTRASOUND TO INTENSIFY OF FOOD DRY MINERALIZATION BY THE OXIDANTS IN VAPOR FORM
}

Abstract: The using of the combined action of the oxidant vapors and ultrasound for the intensification of food products dry mineralization were studied. It is shown the using of ultrasound improves the rapidity of the process in 10-12 times and metrological characteristics of the analysis in comparison with the using only oxidants in vapor form.

Key words: dry mineralization, ultrasound, oxidant vapors, metrological characteristics.

Language: Russian

Citation: Yurchenko OI, Baklanov AN, Belova EA, Kalinenko OS, Baklanova LV (2015) ULTRASOUND TO INTENSIFY OF FOOD DRY MINERALIZATION BY THE OXIDANTS IN VAPOR FORM. ISJ Theoretical \& Applied Science 07 (27): 122-129.

Soi: http://s-o-i.org/1.1/TAS-07-27-21 Doi: crossef http://dx.doi.org/10.15863/TAS.2015.07.27.21

\section{УЛЬТРАЗВУК В ИНТЕНСИФИКАЦИИ СУХОЙ МИНЕРАЛИЗАЦИИ ПИЩЕВЫХ ПРОДУКТОВ ОКИСЛИТЕЛЯМИ В ПАРООБРАЗНОЙ ФОРМЕ}

Аннотация: Изучено использование совместного действия паров окислителей и воздействия ультразвука для интенсификации сухой минерализации пищевых продуктов. Показано, что использование ультразвука позволяет повысить экспрессность прочесса в 10-12 раз и улучшить метрологические характеристики результатов анализа по сравнению с использованием только окислителей в парообразной форме.

Ключевые слова: сухая минерализация, ультразвук, пары окислителей, метрологические характеристики.

Введение. Сухая минерализация, заключающаяся в сжигании проб пищевых продуктов в электропечах при температуре 450$500{ }^{\circ} \mathrm{C}$, широко применяется в лабораторной практике вследствие простоты аппаратурного оформления и возможности одновременной минерализации значительного количества проб (до шестидесяти и более) без необходимости постоянного присутствия персонала лаборатории. Существенным недостатком сухой минерализации является еe длительность, 
составляющая от 5 до 40 часов в зависимости от вида пищевого продукта [1-4].

Процесс сухой минерализации протекает в две основных стадии: 1) сухая перегонка органического вещества, в конце которого озоленная проба полностью обугливается; 2) окисление всего углерода до $\mathrm{CO}_{2}$ и, как результат - получение золы. Повышение температуры на первой стадии должно быть таким, чтобы обеспечить медленное обугливание пробы, при бурном протекании сухой перегонки проба разбрызгивается и как результат - теряются определяемые элементы. Температура на второй стадии минерализации должна быть $450-500{ }^{\circ} \mathrm{C}$, чтобы обеспечить окисление всего углерода до $\mathrm{CO}_{2}$, при этом зола окрашивается в белый или бело-серый цвет [5].

Действующими

государственными стандартами $[6,7]$ допускается интенсификация сухой минерализации инфракрасным (ИК) излучением от ИК-лампы мощностью 500 Вт. Это позволяет сократить процесс на 10-12\%.

Нами ранее был предложен метод ускоренной сухой минерализации пищевых продуктов [8], который заключается в следующем. Первая стадия сухой минерализации интенсифицируется ИК облучением, а на второй стадии - обугленная проба пищевого продукта подвергается непрерывной обработке парами окислителей - оксидами азота или хлором в течение 10-30 мин. Далее проба переносится в муфельную печь и выдерживается при температуре 450-500 ${ }^{\circ} \mathrm{C}$ до появления золы белого или бело-серого цвета. При этом экспрессность сухой минерализации по сравнению с классическим вариантом повышается в 2,0-3,5 раза [8]. Недостатком такого метода является сложность процесса навеска пробы обугливается на электроплитке, затем обрабатывается в реакторе парами окислителей, далее переносится в муфельную печь. Кроме того, метод также длителен и занимает от 2 до 15 ч. Длительность второй стадии минерализации обусловлена тем, что обугленная проба находится в реакторе в виде плотной массы и пары окислителей не могут одновременно воздействовать на всю пробу, в связи с чем только воздействием парами окислителей невозможно окислить всю пробу до $\mathrm{CO}_{2}$ и необходима длительная обработка в муфельной печи при температуре $450-500{ }^{\circ} \mathrm{C}$ [8].

В химической технологии известна сушка различных продуктов в «кипящем слое». При этом, каждая частица материала, подвергаемого сушке, «кипит» в слое теплоносителя и процесс интенсифицируется за счет значительного улучшения контакта материала с теплоносителем [9]. В аналитической химии этот прием не использовался.

С целью ускорения процессов сухой минерализации предлагается использовать совместное действие ИК-облучения и непрерывного потока окислителей в парообразной форме в кипящем слое обугленной пробы пищевого продукта. Для создания эффекта кипящего слоя предлагается использовать воздействие ультразвука. Целью работы является сокращение времени минерализации пищевых продуктов за счет использования эффекта кипящего слоя.

Экспериментальная часть. Сухую минерализацию пищевых продуктов проводили с использованием прибора, схема которого приведена на рис. 1

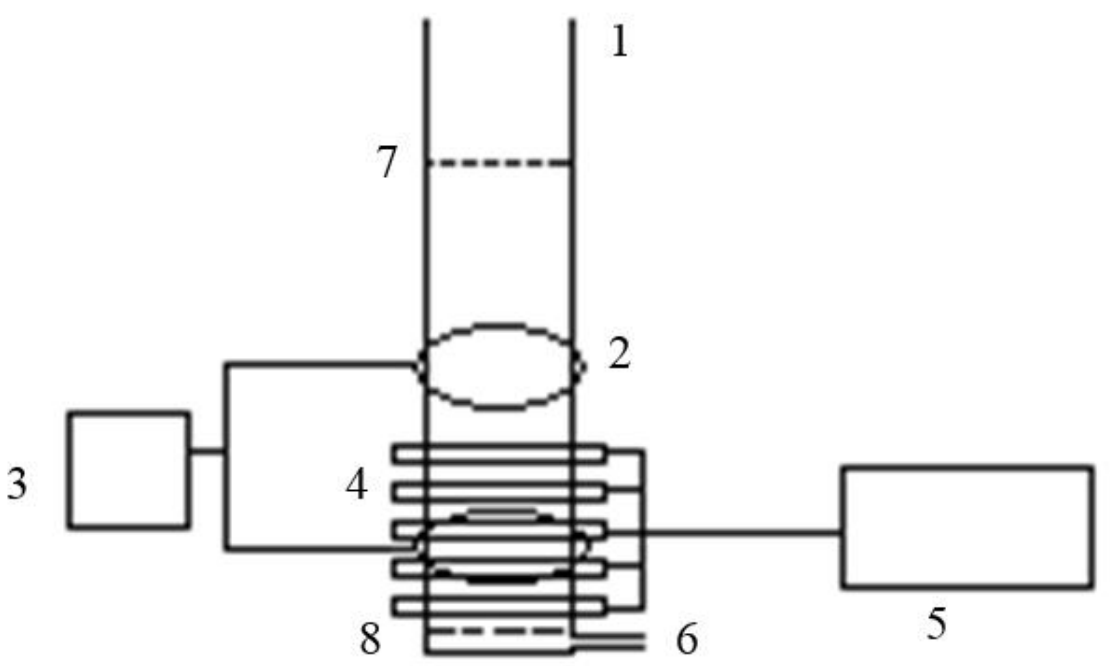

Рисунок 1 - Прибор для интенсификации минерализации пищевых продуктов воздействием ультразвука.

1 - цилиндрический квариевый реактор; 2 - нихромовые термоэлементы; 3 - лабораторный автотрансформатор; 4 - пьезоэлектрические излучатели ультразвука; 5 - генератор ультразвука; 6 подача газообразных окислителей; 7 - сетка из пористого стекла; 8 - сетка из нанопористого стекла. 
Техника эксперимента. Твердые продукты питания измельчали, жидкие - перемешивали. На аналитических весах взвешивали навеску пробы пищевого продукта животного происхождения массой 7,00 г; растительного - 10,00 г и помещали в цилиндрический кварцевый реактор - 1, содержащий вплавленные нихромовые термоэлементы - 2, которые подключаются к лабороторному автотрансформатору - 3 , благодаря чему возможно плавное повышение температуры до $300^{\circ}$ С. На кварцевый реактор одевали кольцеобразные пьезоэлектрические излучатели ультразвука - 4, подключенные к генератору ультразвука - 5, позволяющие создавать ультразвуковые колебания частотой от 500 кГц до 5 МГц. Пробу пищевого продукта осторожно высушивали, затем, постепенно повышая температуру, обугливали, не допуская разбрызгивания. При этом, пробу облучали от ИК-лампы 500 Вт. Расстояние от лампы до пробы в реакторе и температуру нагрева регулировали таким образом, чтобы не допустить разбрызгивания пробы. После обугливания, пробу осторожно измельчали с помощью стеклянного пестика, который ополаскивали бидистиллированной водой. Воду осторожно выпаривали. Далее на систему воздействовали ультразвуком частотой 2,0-5,0 МГц,

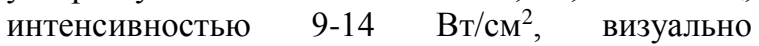
контролировали появление эффекта кипящего слоя. Систему подогревали до $50-80{ }^{\circ} \mathrm{C}$ и подавали газообразный окислитель [8]. В качестве окислителей использовали: 1) хлор, полученный при взаимодействии соляной кислоты и пероксида водорода; 2) оксиды азота (пары), полученные при кипячении азотной кислоты; 3) оксиды азота (пары), полученные при нагревании нитрата аммония и концентрированной азотной кислоты; 4) оксиды азота (пары), полученные при нагревании смеси азотной и серной кислот.

Процесс заканчивали при появлении золы белого или светло-серого цвета без выразительных темных включений. После охлаждения, пробу растворяли в 5-6 мл азотной кислоты (1: 1) и переносили в мерную колбу вместимостью 10 мл, доводили объем раствора бидистиллированной водой метки и тщательно перемешивали. Свинец и кадмий определяли в полученном минерализате непламенным атомноабсорбционным методом согласно [8].

Определяли степень извлечения свинца и кадмия, как отношение найденного количества свинца и кадмия в \% от введенного количества при различных параметрах ультразвука: частота 2,0-5,0 МГц, интенсивность 9-14 Вт/см². Свинец и кадмий вводили в пробу перед минерализацией в виде раствора и перемешивали. Каждый опыт повторяли трижды.

Также, степень извлечения свинца и кадмия проверяли следующим образом. Для этого в пищевых продуктах определяли содержание свинца и кадмия после мокрой и сухой минерализации [8, 9], каждое определение повторяли трижды. За действительное содержание свинца и кадмия принимали среднее арифметическое полученных результатов. Степень извлечения определяли как отношение найденного количества свинца и кадмия от действительного количества в \%.

Результаты и их обсуждение. В табл. 1 приведено влияние различных окислителей и действие ультразвука на время минерализации. С табл. 1 следует, что изменение вида окислителя, хлора или оксидов азота, практически не влияло на время минерализации. Следует также отметить, что без использования окислителей полная минерализация невозможна. Даже повышение температуры до $300{ }^{\circ} \mathrm{C}$ в течение 20 часов не обеспечивает получения золы белого или бело-серого цвета (табл.2). С табл. 1 также следует, что без действия ультразвука полная минерализация невозможна. Даже действие паров окислителей в течение 10 ч не обеспечивает получения золы белого или бело-серого цвета.

В табл. 2. приведены результаты испытаний влияния частоты ультразвука на степень извлечения свинца и кадмия.

\section{Влияние разных окислителей и действие ультразвука на время сухой минерализации.}

\begin{tabular}{|c|c|c|}
\hline $\begin{array}{c}\text { Название продукта. } \\
\text { Окислитель }\end{array}$ & $\begin{array}{c}\text { Время обугливание } \\
\text { пробы с ИК лампою, } \\
\text { мин. }\end{array}$ & $\begin{array}{c}\text { Обработка парами окислителя с ультразвуковой } \\
\text { интенсификацией до получения золы белого или бело- } \\
\text { серого цвета, мин. }\end{array}$ \\
\hline 1 & 2 & \multicolumn{1}{c|}{3} \\
\hline $0^{*}$ & 30 & $\begin{array}{l}\text { Без введения окислителей полного окисления (появление } \\
\text { золы белого или бело-серого цвета) не наблюдалось при } \\
\text { повышении температуры до 300 }{ }^{\circ} \text { на протяжении 20 ч }\end{array}$ \\
\hline $00^{*}$ & 30 & $\begin{array}{l}\text { Без использования ультразвука полного окисления } \\
\text { (появление золы белого или бело-серого цвета) не } \\
\text { наблюдалось на протяжении 10 ч }\end{array}$ \\
\hline
\end{tabular}

ISPC Intelligent technologies, 


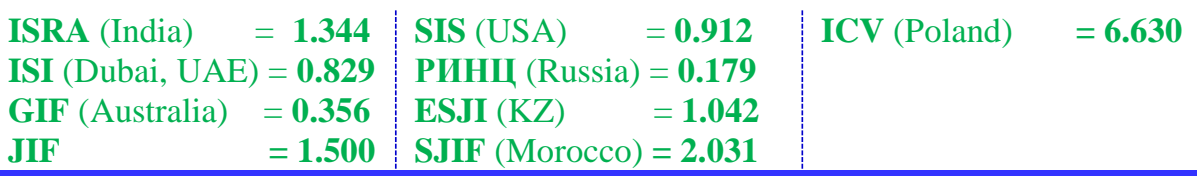

\begin{tabular}{|c|c|c|}
\hline 1 & 30 & 17 \\
\hline 1 & 30 & 15 \\
\hline 1 & 32 & 16 \\
\hline 2 & 30 & 15 \\
\hline 2 & 31 & 16 \\
\hline 2 & 30 & 15 \\
\hline 3 & 35 & 16 \\
\hline 3 & 35 & 17 \\
\hline 3 & 36 & 16 \\
\hline 4 & 35 & 15 \\
\hline 4 & 37 & 16 \\
\hline 4 & 35 & 15 \\
\hline
\end{tabular}

Без введения окислителей полного окисления (появление золы белого или бело-серого цвета) не наблюдалось при повышении температуры до $300^{\circ} \mathrm{C}$ на протяжении 20 ч

Без использования ультразвука полного окисления (появление золы белого или бело-серого цвета) не наблюдалось на протяжении 10 ч

\begin{tabular}{|c|c|c|}
\hline 1 & & набюдалось на протяжении \\
\hline 1 & 42 & 22 \\
\hline 1 & 41 & 21 \\
\hline 2 & 40 & 20 \\
\hline 2 & 41 & 22 \\
\hline 2 & 42 & 20 \\
\hline 3 & 40 & 22 \\
\hline 3 & 41 & 21 \\
\hline 4 & 40 & 20 \\
\hline 4 & 42 & 21 \\
\hline 4 & 41 & 22 \\
\hline
\end{tabular}

Без введения окислителей полного окисления (появление золы белого или бело-серого цвета) не наблюдалось при повышении температуры до $300{ }^{\circ} \mathrm{C}$ на протяжении 20 часов

\begin{tabular}{|l|l|l|}
\hline $00 * * *$ & часов & \\
\hline & 45 & $\begin{array}{l}\text { Без использования ультразвука полного окисления } \\
\text { (появление золы белого или бело-серого цвета) не } \\
\text { наблюдалось на протяжении 10 часов }\end{array}$ \\
\hline
\end{tabular}

\begin{tabular}{|c|c|c|}
\hline & & наблдалось на протяжении 10 часов \\
\hline 1 & 45 & 31 \\
\hline 1 & 47 & 29 \\
\hline 2 & 45 & 30 \\
\hline 2 & 46 & 31 \\
\hline 2 & 45 & 30 \\
\hline 3 & 47 & 29 \\
\hline 3 & 44 & 30 \\
\hline 3 & 45 & 30 \\
\hline 4 & 45 & 31 \\
\hline 4 & 45 & 30 \\
\hline 4 & 47 & 29 \\
\hline
\end{tabular}

* -Хлеб бельй 1 сорт, ** - Мясо говядина, *** - Масло подсолнечное; 0 - без использования паров окислителей; 00- без использования ультразвука; 1 - хлор, полученный при взаимодействии соляной кислоты и пероксида водорода; 2 - оксиды азота (паров), полученные при кипячении азотной кислотыл; 3 оксиды азота (паров), полученные при нагревании нитрата аммония и концентрованной азотной кислоты; 4 - оксиды азота (паров), полученные при нагревании смеси азотной и серной кислот.

ISPC Intelligent technologies, 


\section{Impact Factor:}

\begin{tabular}{l|l|lr} 
ISRA $($ India $)=\mathbf{1 . 3 4 4}$ & SIS $($ USA) & $=\mathbf{0 . 9 1 2}$ \\
ISI $($ Dubai, UAE) & $=\mathbf{0 . 8 2 9}$ & PИНЦ $($ Russia $)$ & $=\mathbf{0 . 1 7 9}$ \\
GIF $($ Australia) & $=\mathbf{0 . 3 5 6}$ & ESJI $($ KZ $)$ & $=\mathbf{1 . 0 4 2}$ \\
JIF & $=\mathbf{1 . 5 0 0}$ & SJIF $($ Morocco $)$ & $=\mathbf{2 . 0 3 1}$
\end{tabular}

Таблица 2

\section{Влияние частоты ультразвука на степень извлечения свинца и кадмия}

\begin{tabular}{|l|c|c|c|c|c|c|c|}
\hline \multirow{2}{*}{$\begin{array}{c}\text { Вид пищевого } \\
\text { продукта }\end{array}$} & \multicolumn{7}{|c|}{ Частота ультразвука, кГц; степень извлечение свинца,\% / степень извлечение } \\
\cline { 2 - 8 } & 2.0 & 2.5 & 3.0 & 3.5 & 4,0 & 4,5 & 5,0 \\
\hline Хлеб белый 1 сорт & $92.0 / 92.7$ & $98.0 / 98.4$ & $98.0 / 98.4$ & $99.0 / 99.4$ & $\begin{array}{c}98.3 / \\
98.8\end{array}$ & $97.8 / 98.2$ & $\begin{array}{c}89.0 / \\
90.2\end{array}$ \\
\hline Мясо говядина & $87.3 / 88.5$ & $96.0 / 96.6$ & $96.2 / 96.4$ & $97.0 / 99.4$ & $\begin{array}{c}96.3 / \\
98.8\end{array}$ & $96.4 / 96.6$ & $\begin{array}{c}84.3 / \\
85.4\end{array}$ \\
\hline Масло подсолнечное & $86.1 / 86.4$ & $95.5 / 95.8$ & $95.3 / 95.8$ & $95.3 / 95.7$ & $\begin{array}{c}95.4 / \\
95.9\end{array}$ & $95.0 / 95.6$ & $\begin{array}{c}85.0 / \\
87.7\end{array}$ \\
\hline
\end{tabular}

В этой таблице и в последующих представлень усредненнье результать трех исследований. Температуру проиесса поддерживали - $(65 \pm 1)^{\circ}$ C. Обработку обугленной пробы проводили ультразвуком интенсивностью $11 \mathrm{Bm} / \mathrm{cm}^{2}$. В качестве окислителя использовали хлор, полученньй при взаимодействии соляной кислоты и пероксида водорода.

В табл. 2. показано, что лучшие результаты были получены при использовании ультразвука частотой 2.5-4.5 МГц [10]. Следует также отметить, что именно при этих параметрах ультразвука наблюдался наиболее выраженный эффект кипящего слоя, благодаря чему каждая частица пробы подвергалась воздействию газообразного окислителя.

В табл. 3. приведены результаты опытов по влиянию интенсивности ультразвука на степень извлечения свинца и кадмия.

Таблица 3

Влияние интенсивности ультразвука на степень извлечения свинца и кадмия.

\begin{tabular}{|c|c|c|c|c|c|c|c|}
\hline \multirow{2}{*}{$\begin{array}{c}\text { Вид пищевого } \\
\text { продукта }\end{array}$} & \multicolumn{7}{|c|}{ Интенсивность ультразвука, Вт/см ${ }^{2}$ с степень извлечение свинца,\% / степень } \\
\cline { 2 - 8 } & 8.0 & 8.5 & 9.0 & 10.0 & 11.0 & 12.0 & 12.5 \\
\hline \multirow{2}{*}{ Хлеб белый 1 сорт } & $84.0 /$ & \multirow{2}{*}{$96.5 / 96.8$} & $97.1 /$ & $97.0 /$ & $98.0 /$ & $98.4 /$ & $52.3 /$ \\
& 85.1 & & 97.5 & 97.8 & 98.4 & 99.2 & 53.6 \\
\hline \multirow{2}{*}{ Мясо говядина } & \multirow{2}{*}{$83.2 / 83.7$} & \multirow{2}{*}{$94.1 / 94.5$} & $95.2 /$ & $95.5 /$ & $96.2 /$ & $97.0 /$ & $50.5 /$ \\
& & 95.4 & 95.8 & 96.4 & 97.4 & 51.1 \\
\hline Масло & \multirow{2}{*}{$82.3 / 82.9$} & \multirow{2}{*}{$93.2 / 93.7$} & $94.3 /$ & $94.7 /$ & $95.3 /$ & $95.6 /$ & $47.4 /$ \\
подсолнечное & & 94.8 & 94.9 & 95.8 & 96.2 & 47.8 \\
\hline
\end{tabular}

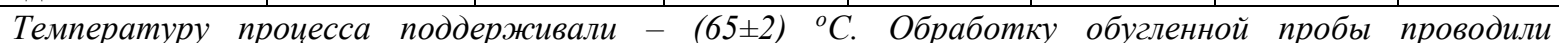
ультразвуком частотою 3.0 МГи. В качестве окислителя использовали хлор, полученньй при взаимодействии соляной кислоть и пероксида водорода.

В табл. 3. показано, что лучшие результаты были получены при использовании ультразвука

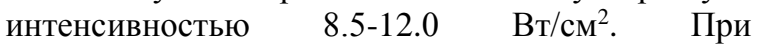
интенсивности ультразвука более $12.5 \mathrm{Bт} / \mathrm{cm}^{2}$ спокойное «кипение» переходило в резкую стадию с разбрызгиванием пробы, приводило к потерям пробы и определяемых элементов.

В табл. 4 приведены результаты исследований влияния температуры процесса на время минерализации проб пищевых продуктов.
С табл. 4 следует, что уменьшение температуры процесса менее $60{ }^{\circ} \mathrm{C}$ приводит к уменьшению скорости химических реакций окисления проб пищевых продуктов и как результат - к увеличению времени анализа (табл.6). Повышение температуры процесса более $70{ }^{\circ} \mathrm{C}$ переводит его в бурную фазу и приводит к потерям части проб пищевых продуктов, и получению недостоверных результатов анализа.

Влияние температуры процесса на время минерализации.

Таблица 4

\begin{tabular}{|c|c|c|c|c|c|c|c|}
\hline \multirow{2}{*}{$\begin{array}{c}\text { Вид пищевого } \\
\text { продукта }\end{array}$} & \multicolumn{7}{|c|}{ Температура процесса, ${ }^{\circ} \mathrm{C}$; время минерализации, мин. } \\
\hline & 50 & 55 & 60 & 65 & 70 & 75 & 80 \\
\hline $\begin{array}{c}\text { Хлеб белый } 1 \\
\text { сорт }\end{array}$ & $100 \pm 2$ & $70 \pm 2$ & $50 \pm 2$ & $45 \pm 2$ & $45 \pm 2$ & $\begin{array}{r}\text { Процес } \\
\text { с окисления }\end{array}$ & $\begin{array}{r}\text { Процес } \\
\text { с окисления }\end{array}$ \\
\hline Мясо говядина & $127 \pm 2$ & $86 \pm 2$ & $65 \pm 2$ & $62 \pm 2$ & $62 \pm 2$ & пищевы & пищевы \\
\hline
\end{tabular}

ISPC Intelligent technologies, 


\begin{tabular}{|c|c|c|c|c|c|c|c|}
\hline $\begin{array}{c}\text { Масло } \\
\text { подсолнечное }\end{array}$ & $143 \pm 2$ & $98 \pm 2$ & $78 \pm 2$ & $75 \pm 2$ & $75 \pm 2$ & $\begin{array}{l}\text { х продуктов } \\
\text { переходит в } \\
\text { резкую } \\
\text { стадию, } \\
\text { визуально } \\
\text { наблюдается } \\
\text { потеря } \\
\text { части пробы }\end{array}$ & $\begin{array}{l}\text { х продуктов } \\
\text { переходит в } \\
\text { резкую } \\
\text { стадию, } \\
\text { визуально } \\
\text { наблюдается } \\
\text { потеря } \\
\text { части пробы }\end{array}$ \\
\hline
\end{tabular}

Обработку обугленной пробы проводили ультразвуком частотою 3.0 МГи, интенсивностью 11 Вm/см². В качестве окислителя использовали хлор, полученный при взаимодействии соляной кислоты и пероксида водорода.

В результате проведенных опытов нами предложен новый прием в аналитической химии пищевых продуктов - использование совместного действия паров окислителей и воздействия ультразвука для интенсификации сухой минерализации пищевых продуктов. Причем, ультразвук использовался для создания эффекта кипящего слоя, благодаря чему каждая частичка пробы обугленного пищевого продукта вступает в химические реакции окисления с непрерывно поступающим окислителем в газообразной форме. В связи с чем, необходимость в третьей стадии минерализации - длительной обработке пробы в электропечи при температуре $450-500{ }^{\circ} \mathrm{C}$ отпала и скорость минерализации возросла в 1012 раз (табл.5).

Таблица 5

\section{Сравнение способов минерализации пищевых продуктов.}

\begin{tabular}{|c|c|c|c|c|c|c|c|c|}
\hline \multirow{3}{*}{$\begin{array}{c}\text { Вид } \\
\text { пищевого } \\
\text { продукта }\end{array}$} & \multicolumn{4}{|c|}{ Способ с ультразвуком } & \multicolumn{4}{|c|}{ Способ без ультразвука } \\
\hline & \multirow[t]{2}{*}{$\begin{array}{c}\text { Время } \\
\text { минерал } \\
\text { изации, } \\
\text { мин. }\end{array}$} & \multirow[t]{2}{*}{$\begin{array}{c}\text { Кол-во } \\
\text { стадий } \\
\text { минерал } \\
\text { изации }\end{array}$} & \multicolumn{2}{|c|}{$\begin{array}{c}\text { Относительное } \\
\text { стандартное } \\
\text { отклонение } \mathrm{Sr} \\
(\mathrm{P}=0.95 ; \mathrm{n}=6)\end{array}$} & \multirow[t]{2}{*}{$\begin{array}{c}\text { Время } \\
\text { минерализ } \\
\text { ации, мин. }\end{array}$} & \multirow[t]{2}{*}{$\begin{array}{c}\text { Кол-во } \\
\text { стадий } \\
\text { минерал } \\
\text { изации }\end{array}$} & \multicolumn{2}{|c|}{$\begin{array}{c}\text { Относительное } \\
\text { стандартное } \\
\text { отклонение } \mathrm{Sr} \\
(\mathrm{P}=0.95 ; \mathrm{n}=6)\end{array}$} \\
\hline & & & $\mathrm{Pb}$ & $\mathrm{Cd}$ & & & $\mathrm{Pb}$ & $\mathrm{Cd}$ \\
\hline $\begin{array}{c}\text { Хлеб белый } \\
1 \text { сорта }\end{array}$ & $45 \pm 2$ & 2 & $\begin{array}{c}0.082- \\
0.085\end{array}$ & $\begin{array}{c}0.076- \\
0.079\end{array}$ & $600 \pm 60$ & 3 & $\begin{array}{c}0.092- \\
0.095\end{array}$ & $\begin{array}{c}0.083- \\
0.087\end{array}$ \\
\hline $\begin{array}{c}\text { Мясо } \\
\text { свинина } \\
\end{array}$ & $65 \pm 2$ & 2 & $\begin{array}{r}0.087- \\
0.089 \\
\end{array}$ & $\begin{array}{c}0.075- \\
0.078 \\
\end{array}$ & $1260 \pm 120$ & 3 & $\begin{array}{c}0.100- \\
0.101 \\
\end{array}$ & $\begin{array}{c}0.084- \\
0.087 \\
\end{array}$ \\
\hline $\begin{array}{c}\text { Молоко } \\
\text { пастеризова } \\
\text { нное }\end{array}$ & $60 \pm 2$ & 2 & $\begin{array}{c}0.088- \\
0.090\end{array}$ & $\begin{array}{c}0.076- \\
0.078\end{array}$ & $960 \pm 120$ & 3 & $\begin{array}{c}0.100- \\
0.102\end{array}$ & $\begin{array}{c}0.084- \\
0.087\end{array}$ \\
\hline
\end{tabular}

1 стадия минерализации - обугливание; 2 стадия - окисление остаточного органического вещества; 3 стадия-окончание процессов окисления в электрическом муфельном шкафу при температуре $450-500{ }^{\circ} \mathrm{C}$.

На основании нового способа минерализации нами разработана методика экспрессного определения свинца и кадмия в пищевых продуктах электротермическим атомноабсорбционным методом. Правильность методики проверялась сравнением результатов анализа одних и тех же проб с использованием методики, основанной на использовании сухой минерализации только парами окислителей [8].

Таблица 6

Сравнение метрологических характеристик способов минерализации проб пищевых продуктов при определение свинца и кадмия.

\begin{tabular}{|c|c|c|c|c|c|c|}
\hline \multirow{3}{*}{$\begin{array}{l}\text { Название } \\
\text { продукта }\end{array}$} & \multicolumn{2}{|c|}{$\begin{array}{l}\text { Введено } \mathrm{Pb} \text { и } \mathrm{Cd} \\
\quad \text { по мг/кг }\end{array}$} & \multicolumn{4}{|c|}{$\begin{array}{c}\text { Найдено микроэлементов, мг/г. Относительное стандартное } \\
\text { отклонение } \mathrm{Sr}(\mathrm{P}=0.95 ; \mathrm{n}=6)\end{array}$} \\
\hline & & & \multirow{2}{*}{$\mathrm{Pb}$} & \multirow{2}{*}{$\mathrm{S}_{\mathrm{r}}$} & \multirow{2}{*}{$\mathrm{Cd}$} & \multirow{2}{*}{$\mathrm{S}_{\mathrm{r}}$} \\
\hline & $\mathrm{Pb}$ & $\mathrm{Cd}$ & & & & \\
\hline \multicolumn{7}{|c|}{ Предлагаемый способ минерализации с ультразвуком } \\
\hline \multirow{2}{*}{ Мясо свинина } & 0 & 0 & $0.122 \pm 0.010$ & 0.089 & $0.045 \pm 0.003$ & 0.078 \\
\hline & 0.100 & 0.050 & $0.204 \pm 0.016$ & 0.087 & $0.100 \pm 0.007$ & 0.075 \\
\hline Рыба «Тунец» & 0 & 0 & $0.101 \pm 0.009$ & 0.093 & $0.019 \pm 0.001$ & 0.079 \\
\hline
\end{tabular}

ISPC Intelligent technologies,

Marseille, France 


\section{Impact Factor:}

\begin{tabular}{lr|lr} 
ISRA $($ India $)$ & $=\mathbf{1 . 3 4 4}$ & SIS $($ USA $)$ & $=\mathbf{0 . 9 1 2}$ \\
ISI $($ Dubai, UAE) $=\mathbf{0 . 8 2 9}$ & PИНЦ $($ Russia $)=\mathbf{0 . 1 7 9}$ \\
GIF $($ Australia $)=\mathbf{0 . 3 5 6}$ & ESJI $($ KZ $)$ & $=\mathbf{1 . 0 4 2}$ \\
JIF & $=\mathbf{1 . 5 0 0}$ & SJIF $($ Morocco $)=\mathbf{2 . 0 3 1}$
\end{tabular}

\begin{tabular}{|c|c|c|c|c|c|c|}
\hline охлажденный & 0.200 & 0.020 & $0.299 \pm 0.084$ & 0.084 & $0.040 \pm 0.003$ & 0.072 \\
\hline \multirow{2}{*}{ Молоко пастеризованное } & 0 & 0 & $0.074 \pm 0.006$ & 0.090 & $0.012 \pm 0.001$ & 0.076 \\
\hline & 0.100 & 0.020 & $0.182 \pm 0.015$ & 0.088 & $0.030 \pm 0.002$ & 0.078 \\
\hline \multirow[t]{2}{*}{ Крупа пшеничная, в/с } & 0 & 0 & $0.147 \pm 0.011$ & 0.082 & $0.013 \pm 0.001$ & 0.075 \\
\hline & 0.150 & 0.020 & $0.305 \pm 0.023$ & 0.080 & $0.029 \pm 0.002$ & 0.073 \\
\hline \multirow{2}{*}{ Хлеб «Урожайный» } & 0 & 0 & $0.073 \pm 0.006$ & 0.082 & $0.039 \pm 0.003$ & 0.076 \\
\hline & 0.100 & 0.030 & $0.158 \pm 0.012$ & 0.085 & $0.065 \pm 0.005$ & 0.079 \\
\hline \multirow[t]{2}{*}{ Яблока } & 0 & 0 & $0.059 \pm 0.005$ & 0.086 & $0.016 \pm 0.001$ & 0.071 \\
\hline & 0.100 & 0.020 & $0.171 \pm 0.014$ & 0.088 & $0.033 \pm 0.002$ & 0.073 \\
\hline \multicolumn{7}{|c|}{ Способ минерализации без ультразвука } \\
\hline \multirow{2}{*}{ Мясо свинина } & 0 & 0 & $0.144 \pm 0.013$ & 0.101 & $0.012 \pm 0.004$ & 0.085 \\
\hline & 0.100 & 0.050 & $0.231 \pm 0.022$ & 0.101 & $0.030 \pm 0.008$ & 0.081 \\
\hline \multirow{2}{*}{$\begin{array}{l}\text { Рыба «Тунец» } \\
\text { охлажденный }\end{array}$} & 0 & 0 & $0.780 \pm 0.073$ & 0.101 & $0.042 \pm 0.003$ & 0.082 \\
\hline & 0.200 & 0.020 & $0.988 \pm 0.087$ & 0.095 & $0.059 \pm 0.005$ & 0.089 \\
\hline \multirow{2}{*}{ Молоко пастеризованное } & 0 & 0 & $0.084 \pm 0.008$ & 0.100 & $0.014 \pm 0.001$ & 0.084 \\
\hline & 0.100 & 0.020 & $0.172 \pm 0.016$ & 0.100 & $0.032 \pm 0.003$ & 0.087 \\
\hline \multirow[t]{2}{*}{ Крупа пшеничная, в/с } & 0 & 0 & $0.246 \pm 0.023$ & 0.100 & $0.016 \pm 0.001$ & 0.082 \\
\hline & 0.150 & 0.020 & $0.393 \pm 0.034$ & 0.094 & $0.032 \pm 0.003$ & 0.085 \\
\hline \multirow{2}{*}{ Хлеб «Урожайный» } & 0 & 0 & $0.081 \pm 0.007$ & 0.095 & $0.033 \pm 0.003$ & 0.087 \\
\hline & 0.100 & 0.030 & $0.160 \pm 0.014$ & 0.092 & $0.064 \pm 0.005$ & 0.083 \\
\hline \multirow[t]{2}{*}{ Яблока } & 0 & 0 & $0.071 \pm 0.007$ & 0.101 & $0.012 \pm 0.001$ & 0.085 \\
\hline & 0.100 & 0.020 & $0.154 \pm 0.013$ & 0.093 & $0.030 \pm 0.002$ & 0.081 \\
\hline
\end{tabular}

Из результатов опытов приведенных в табл.6 следует, что наиболее точные результаты анализа пищевых продуктов могут быть получены при использовании способа минерализации парами окислителей с интенсификацией процесса ультразвуком. Так, при использовании способа сухой минерализации только парами окислителей, относительное стандартное отклонение результатов анализа составляет $\mathrm{S}_{\mathrm{r}}=0,081-0,089$ при определение кадмия и $\mathrm{S}_{\mathrm{r}}=0,092-0,101$ при определение свинца; а в способе, который предлагается соответственно $\mathrm{Sr}=0,071-0,079$ и $\mathrm{S}_{\mathrm{r}}=0,082$ 0,090 .

Выводы. Результаты работы свидетельствуют, что использование ультразвука частотой 2.5 - 4.0 МГц, интенсивностью 8.5 $12.0 \mathrm{BT} / \mathrm{cm}^{2}$ для интенсификации процесса окисления обугленных пищевых продуктов парами газообразных окислителей - хлора или оксидов азота при температуре 60-70 ${ }^{\circ} \mathrm{C}$ позволяет уменьшить время минерализации, упростить способ пробоподготовки и улучшить метрологические характеристики результатов анализа.

\section{References:}

1. (1992) Atomno-absorbtsionnye metody opredeleniya toksichnykh elementov $\mathrm{V}$ pishchevykh produktakh i pishchevom syr'e. Metodicheskie ukazaniya Utverzhdeny Gosudarstvennym komitetom sanitarnoepidemiologicheskogo nadzora Rossiiskoi Federatsii, 25 dec 1992. N 01-19/47-11.

2. Akinyele IO, Shokunbi OS (2015) Comparative analysis of dry ashing and wet digestion methods for the determination of trace and heavy metals in food samples. Food Chemistry. - 2015. - Vol. 173. - pp. 682-684.

3. Dugo G, Bella GD, Rando R, Saitta M (2012) Sample preparation for the determination of metals in food samples. Comprehensive
Sampling and Sample Preparation: Analytical Techniques for Scientists. - Elsevier, 2012. pp. 495-519.

4. Ramon DSJ, Barnes M, Krug FJ (2014) Introduction to sample preparation for trace element determination. Microwave-Assisted Sample Preparation for Trace Element Determination. - Elsevier, 2014. - pp. 1-58.

5. Chmilenko FO, Baklanov OM, Bokhan YV (2005) Sposib mineralizatsii kharchovikh produktiv. Patent Ukraïni № 72156 A.-opubl. 17.01.2005, byul. № 1 .

6. (1994) GOST 26929-94 Syr'e i produkty pishchevye. Podgotovka prob. Mineralizatsiya 


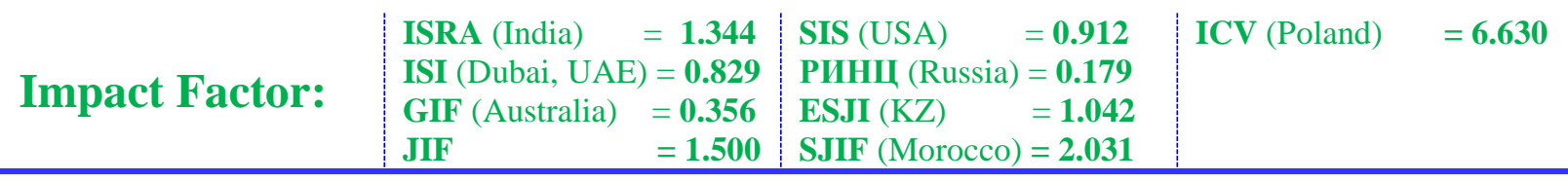

dlya opredeleniya soderzhaniya toksichnykh elementov.

7. (1996) GOST 30178-96 Syr'e i produkty pishchevye. Atomno-absorbtsionnyi metod opredeleniya toksichnykh elementov.

8. Yurchenko OI, Baklanov AN, Belova EA, Baklanova LV, et al. (2015) Intensifikatsiya sukhoi mineralizatsii pishchevykh produktov parami okislitelei i IK-oblucheniem. Ukrainskii khimicheskii zhurnal.- 2015.- T.81, № 4. - pp. 98-102.
9. Kalinenko OS, Yurchenko OI, Baklanova LV (2014) Patent Ukraïnm na korisnu model' №94654. Sposib pidgotovki prob zhiriv i olii dlya viznachennya plyumbumu ta kadmiyu. Data, z yakoï $\mathrm{e}$ chinnimi prava 25.11.2014.

10. Baklanov AN, Avdeenko AP, Konovalova SA, Baklanova LV (2012) Ul'trazvuk V analiticheskoi khimii i khimicheskoi tekhnologi: monografiya. - Kramatorsk: DGMA, 2012. - 332 p. 